\title{
Conceptualising Teacher Vision as a Possible Framework for Transformative Teacher Professionalism
}

\begin{abstract}
SUMMARY
The characterisation of quality teachers differs in transformative teacher professionalism. It represents a more dynamic and proactive teaching profession. This paper reports on conceptualising teacher vision based on the related literature and recommends it as a possible framework for transformative teacher professionalism. Following the explanation of transformative teacher professionalism and teaching as a mature profession, characterisation and conceptualisation of teacher vision are addressed. Then an attempt to justify teacher vision as a possible framework for transformative teacher professionalism is done. The paper ends with a set of recommendations for the use of teacher vision in further research on teacher professionalism and teacher education.

KEY WORDS: Transformative teacher professionalism, teaching as a mature profession, quality teacher, teacher vision
\end{abstract}

\section{Introduction}

There is no argument that everyone - states, schools, teachers, parents and students - wishes to have quality teachers. As expectations from educational practices grow in society, so do quality levels of teachers. The very recent tragic pandemic Covid-19 has once preoccupied our minds to seek quality teachers who can adapt to emerging circumstances efficiently. Although there has been a vast body of rigorous research and practices towards educating quality teachers, teaching as a profession and teacher professionalism are still a matter of complexity (Sachs, 2016). This seems to be mainly because of the multi-dimensional structure of being a teacher and each attempt to any dimension of teaching as a profession appears to help develop quality teachers. Having such a structure, teacher professionalism has still remained as a concept and field which multi-perspectives are applied to explain and elaborate on. 
Like variations in policies and organisations of teacher professionalism in different countries or states, the term itself and its dimensions have a variety of explanations, which helps conceptualise teacher professionalism in-depth. To illustrate, Ro's (2020) very recent threefold categorisation of managerial, professional and transformative views on teacher professionalism based on the synthesis of previous discussion can be considered among these explanations and contributes to conceptualisation of teacher professionalism by presenting a clear framework for further efforts on this issue. The OECD report also scrutinizes teacher professionalism upon three major domains, namely professional knowledge, teachers' autonomy and peer networks (OECD, 2016). This report displays a detailed approach to the concept as each domain involves the following sub-domains such as formal teacher education, professional development opportunities and practitioner research falling under professional knowledge; autonomy and school-based decision making falling under teachers' autonomy; and mentoring, induction, professional development plans, peer feedback and professional learning communities falling under peer networks.

It is worth pursuing attempts to set a framework for teacher professionalism and amplify earlier research. Such efforts will contribute a lot to draw out a schema for quality teachers as teacher professionalism is highlighted as one of the determinant factors in the quality of learning and teaching in classrooms (Day, 1999). Mockler's (2005) transformative teacher professionalism significantly augments the contested site of teacher professionalism to a more dynamic level. Developing teachers as creative curriculum developers and innovative pedagogues who can take risks to support and sustain learning considering all elements in their contexts appears to be central in Mockler's (2005) transformative teacher professionalism. Correspondingly, the characterization of teacher professionalism as 'mature profession' by Sachs (2016) seems to reflect the dynamic structure of transformative teacher professionalism. Sachs (2016) describes a mature profession as having a multidimensional structure and being more than the sums of its elements which are interconnected, and argues that teaching is precisely a mature profession with its capability to represent itself and involving members having a common set of values and knowledge base. The analytical framework set by Day (1999), Mockler (2005) and Sachs (2016) leads us to seek for characteristics of quality teachers within a transformative nature of teaching which is defined as a mature profession.

This new framework for teaching profession does not seem to match well with characterization of quality teachers from the current perspective 
of controlled professionalism. Mockler (2005) criticises the current context as involving the social trust erosion based on standards, measurement and accountability. In essence, she explains the idealisation of quality teachers from a transformative perspective and specifies their characteristics as adopting risk-taking and collaborative insights. Similarly, Sachs (2016) stands against performance cultures, accountability and standards regimes as factors creating a more conservative and risk-averse context in the teaching profession. Ideal representation of a quality teacher involves establishing trust among and between stakeholders, taking risks in challenging contexts, committing to ongoing professional learning, and contributing to co-production of new knowledge about teaching instead of becoming 'silent witnesses' and 'rendered mute'. Taken together, considering teaching as a mature profession and adopting a transformative perspective to it appear to direct us to a more proactive teaching profession towards quality teachers and there is still a need for such a comprehensive framework that covers the characteristics of quality teachers with proactive roles in the teaching profession.

The purpose of this paper is to address the conceptualisation of the term 'teacher vision' in depth and suggests it as a possible framework in seeking the characteristics of quality teachers within the context of transformative teacher professionalism. In what follows, a characterisation of distinguishing features of teacher vision from similar concepts in teacher education is presented based on the relevant literature first. This characterisation precedes an attempt to reach a common definition for teacher vision depending on the present views in the literature and possible use of teacher vision as a framework for transformative teacher professionalism is justified through clarifying the interrelatedness between them. The paper is concluded with a set of recommendations for the use of teacher vision in teacher professionalism contexts.

\section{Characterisation of teacher vision}

Even a short review on elements of a quality teacher displays us how thorough and superb individuals with high cognitive and metacognitive capacities, expertise in knowledge of policies, standards, subject matters, curricula and assessment, students and their families. In addition, these individuals are expected to show high performance and achievement in their classroom, which refers to their practical competences. Undoubtedly, this situation is not beyond an ideal representation. Nevertheless, every attempt in any context to build a common ground towards such ideals does not only enhance the teacher quality but also accordingly the welfare of the society. 
Over the last twenty years, teacher vision has appeared to be approached more directly as a concept in education and teacher education in particular. To be honest, I encountered the term 'teacher vision' while I was searching for a theoretical framework for my PhD dissertation in 2013. I had already targeted at the experiences of beginning teachers in their first years of teaching and planned to explore what changes appear in their professional understandings and practices. Reviewing the relevant literature motivated me to take teacher vision as a conceptual framework for my study.

Although teacher vision is defined and explained by several scholars in the field of education, the term vision is still much more associated with schools and organisations as highlighted in vision and mission statements. The schools explicitly declared their visions that display their futuristic organisational targets and their missions as organisations in the pursuit of these targets. Unfortunately, it is rare to see such visional statements of teachers. In Turkey, the context I have been teaching at various levels of schools for 17 years, no vision statements for teachers have been declared explicitly. The term 'vision' is often used for the organisational bodies as in the recent education vision statement by the Ministry of National Education (MoNE, 2018). The standards and/or competences for teaching profession are preferred to use in designing teacher education policies and curricula, which reflects a conservative and risk-averse approach towards teaching profession as Sachs (2016) emphasised.

Turning our point to distinguish teacher vision from other similar concepts in education, it seems rational to characterise it first. Fairbanks et al. (2010) explicitly differentiates it from beliefs and theories by characterising teacher vision as 'a teacher's personal commitment to seek outcomes beyond the usual curricular requirement' and 'to inspire children in ways that tend to be more morally than cognitively based (p. 163)'. Similarly, Parsons et al. (2017) distinguish it from a wide variety of constructs related to teaching profession, ideals, beliefs, knowledge and self-concept in particular, as having a more oriented to students instead of teachers themselves. Characterising teacher vision as a personal commitment is also highlighted in Hammerness's (2014) proposed balance of visions. She contends that teacher education programs should lead teachers towards a vision of teaching as neither a professional practice only nor a social or moral aspect. Rather, she suggests promoting a teacher vision which is characterised with an embracing aspect of both social values and professional practices. As a result, teacher vision appears to have a characteristic of personal commitment instead of being highly theoretical. It also has a dynamic structure which can emancipate teachers from 
controlled professionalism and encourage them to enact as adaptive teachers in any context.

\section{Towards a common definition of teacher vision}

Before moving towards a shared common definition for teacher vision, several arguments by various scholars also help characterise teacher vision in depth. These arguments often involve what teacher vision is not instead of direct statements of what it is. To illustrate, Shulman (2006) characterises visions as not being 'untethered dreams' and 'merely expressions of deep political moral values' (p. ix). Likewise, Kennedy (2006) highlights that teacher visions are neither 'religious' nor 'idealistic imaginings' nor 'head-in-the-clouds sense' (p. 207). In addition, Kosnik and Beck (2009) presents a dualistic perspective while explaining teacher vision as a framework for teacher education such that it refers to 'theoretical yet concrete, idealistic yet realistic, and comprehensive yet selective and integrated' (p. 167). These arguments together contribute to any attempt towards a common definition of teacher vision as they set the boundaries in defining it. Within these boundaries, it still does not seem to be likely to reach a common shared definition of teacher vision.

Exploring explicit definitions and explanations can bring us to a common understanding of teacher vision and help us conceptualise the term more specifically. Fortunately, there have been several scholars who address teacher vision. Kosnik and Beck (2009) define teacher vision as teachers' understanding of the goals, principles and practices of teaching. They feature it as a blending concept that integrates the priorities which they refer to as planning, assessment, classroom organisation, subject content, pedagogy and professional identity.

More recently, they take a further step towards elucidating the complex nature of teacher vision and present a list of components towards a precise conceptualisation of teacher vision (Beck \& Kosnik, 2014). These components highlight having a broad teacher role towards student learning, connecting the theories to their own practices and students' way of life and accordingly individualising learning, creating learning communities which foster collaboration and co-learning, favouring inclusion and pursuing a work-life balance. They all appear to be the areas that need to be addressed to reach a broader and deeper interpretation of teacher vision. Beck and Kosnik (2014) call for strengthening teachers in these areas so that they can have a comprehensive vision which enables them to adapt to any challenging situations and to grow as teachers with strong visions. 
The practical aspect of teacher vision is also characterised in Kennedy's (2006) explanation of teacher vision as a concrete and operational plan "with purpose, direction, and momentum" (p. 208). She highlights the operationalised feature of teacher vision by defining it as teachers' decisions based on their sense of purpose and enacting them in their practices to lead the complex and multi-dimensional nature of education.

Another aspect of teacher vision seems to be towards a more personalised feature. Fairbanks et al. (2010) draw a more personalised picture of teacher vision by emphasising teachers' personal commitment in the profession beyond the beliefs and theories only. They also argue that building teacher visions with personal commitment enables teachers to move towards highquality teachers with adaptive pedagogical knowledge and morality. Such a personalised stance is also attributed to teacher vision by other scholars. Among these, Duffy (2002) defines teacher vision as personal positions of teachers that are based on their insights and guides them to think and act independently in their teaching contexts. A developmental feature is also ascribed to teacher vision by Duffy (2002) as referring it as "a career-long sense of becoming" (p. 334). Similarly, Parsons et al. (2017) highlight both personalised and developmental features of teacher vision by attributing the aspects of evolving over time, being shaped by experiences and contextual factors, and guiding teachers' decisions during their practices.

A detailed definition of teacher vision based on clarifying the complex view of the concept is explained by Hammerness (2006). She finds an institutional, future-oriented, rational and positive view towards teacher vision quite oversimplified and suggests a more personalised and emotional understanding of teacher vision which is rooted in both past and present, and can be both inspirational and problematic with the tension between possible ideal images and realities. Briefly, Hammerness (2006) defines teacher vision as teachers' images of ideal classroom practices. These images seem to be built upon teachers' overall understanding of their profession, their perceived roles as teachers and their projections for the future.

Current explanations of teacher vision provide considerable contributions towards conceptualising it and seem to help characterise its several common features. First, teacher vision is distinctive as being a more student-oriented concept instead of teachers themselves. This feature encourages teachers to be proactive and more adaptive in their contexts. Second, teacher vision differs from a rational and technical view of teacher professionalism based on specified standards or competences in that it conveys a more personalised characteristic. Thus teacher vision appears to reflect a bottom-up approach to 
teacher professionalism and presents a more context-oriented view towards it. Third, teacher vision holds a dynamic feature rather than a static one which is based on controlled professionalism. This dynamic feature enables teachers to enhance their visions and empowers them in making decisions autonomously, which also refers to the developmental feature of teacher vision. Finally, teacher vision refers to a collaborative professionalism in that it calls for creating learning communities and favouring co-learning.

Moving back to the search for an appropriate framework for transformative teacher professionalism discussed earlier in his paper, teacher vision with its attributed features appears to be compatible well with the principles of transformative teacher professionalism. The major criticism of both Mockler (2005) and Sachs (2016) against current professionalism based on standards, measurement and accountability underpins the conceptualisation of teacher vision as it refers to both personal commitment and context-oriented view of teacher professionalism rather than to a technical view based on teacher competences and standards. In addition, seeking more dynamic and proactive teachers in transformative teacher professionalism is embodied in the conceptualisation of teacher vision. Taken together, the use of teacher vision as a framework for transformative teacher professionalism appears to be justified well with remarkably similar nature of both.

\section{Conclusion}

This study attempts to conceptualise teacher vision based on presenting an analytic representation of the relevant literature and locate it as a possible framework for transformative teacher professionalism. The conceptual analysis suggests that teacher vision with its attributed features characterised in the relevant literature can be a framework for transformative teacher professionalism which calls for dynamic and proactive quality teachers.

The way in which teacher vision has been conceptualised in this paper is not as a set of specific rules and procedures for what to do, when and how. Rather, one of the suggestions is that further attempts to conceptualise teacher vision and its elements are still needed. Hammerness et al.'s (2005) teacher education model centred upon teacher vision and its elements i.e. understanding, tools, practices and dispositions provide a sound ground for further conceptualisation of teacher vision as the model presents a more analytical framework with a cyclical interdependence among the elements in it. Specifically, I used it as conceptual framework in both my $\mathrm{PhD}$ dissertation which is aimed to examine the changes in beginning teachers' visions (Ergünay, 2018) and the challenges they face during their first year in teaching profession 
(Ergünay \& Adıgüzel, 2019a). The framework appears to facilitate examining the visions of beginning teachers and its elements represent interdependence among themselves. More specifically, the findings in our research study based on data which were collected through classroom observations, interviews and an open-ended questionnaire indicate that the teacher vision-oriented model suggested by Hammerness et al. (2005) is likely to provide a useful framework for researchers who are eager to examine teachers' professional understanding including their subject matter knowledge, pedagogical content knowledge, knowledge of classroom management and relationship with parents, conceptual tools i.e., adopted learning theories and approaches, practical tools i.e., adopted instructional methods and techniques, professional practices i.e., planning, implementation, feedback and correction preferences, and dispositions specified as adopted roles as teachers, the role they attribute to learners, their attitudes towards personal and professionals development.

In addition, we used Hammerness et al.'s a teacher education model in another recent study which is also aimed at examining the changes in beginning teachers' visions (Ergünay \& Adıüzel, 2019b). Once again, the model appears to provide us with a valid conceptual ground in this study. In addition, focusing on the changes in beginning teachers' professional understanding, tools, practices and dispositions separately and then conducting a collective analysis of them centring upon the participants' professional visions i.e., teacher vision facilitated both the data collection and reaching analytical conclusion in our research study.

The paper is concluded with a set of recommendations for the use of teacher vision in teacher professionalism contexts. First, the concept 'teacher vision' has emerged as a recent term which is likely to be integrated into teacher education and teacher professional development policies and practices. Thus the term can enable us to evaluate the current standard or competence based policies and practices from a perspective of transformative teacher professionalism and the concept 'teacher vision' can be used as a starting framework or a common tool.

Teacher vision can also be approached as a controlling mechanism for evaluating the effectiveness of initial teacher education curricula, teacher induction and professional development programs in practice. In addition, teacher development and teacher performance can be monitored through the elements of teacher vision analytically and accordingly a total evaluation can be made based on teacher vision on the condition that visions of teachers are well-diagnosed with effective scales or other assessment tools. Once such 
tools are developed, they also can be used in teacher recruitment and identifying their professional needs.

Finally, it is recommended that further research on teacher vision be undertaken in the following areas:

- Although there is a growing body of literature on teacher vision, the concept still needs broader and deeper conceptualisation based on the relevant theoretical and practical research.

- Further research is needed to elaborate on what constitutes teacher vision and to specify more closely the interdependence between teacher vision and other conceptualisations in education. Clarifying the distinguishing features of teacher vision from these concepts will provide a better understanding of it conceptualisation.

- The literature reviewed and my own research experience suggest that using teacher vision as a framework in a number of possible future educational research more specifically research on teacher education and professional learning will be worthwhile.

- A more comprehensive focus on transformative teacher professionalism and teacher vision concept can develop a better understanding of interdependence between them.

- The relevant literature on teacher vision makes it clear that the concept comprises multiple elements such as teachers' professional understanding, practices, conceptual and practical tools, and their adopted attitudes towards their roles. It is likely that further research will help explore new elements of teacher vision and clarify them. The interdependence of these elements is another study field for further research. The correlations among each element of teacher vision and the directions of these correlations can be of interest to be examined.

\section{REFERENCES}

Beck, C., Kosnik, C. (2014). Growing as a teacher: Goals and pathways of ongoing teacher learning. Rotterdam: Sense.

Day, C. (1999). Developing teachers: The challenges of lifelong learning. London: Falmer.

Duffy, G.G. (2002). Visioning and the development of outstanding teachers. Reading Research and Instruction, 41(4), 331-343. https://doi.org/10.1080/19388070209558375

Ergünay, O. (2018). Aday öğretmenlerin ilk yıl mesleki deneyimlerinin Hammerness, DarlingHammond ve Bransford'un öğretmen eğitimi modeli bağlamında incelenmesi: Bir çoklu durum çalışması [Examining the first year teaching experiences of beginning teachers with Hammerness, Darling-Hammond and Bransford teacher edcucation model: A multi-case $s t u d y$ ]. [Unpublished doctoral thesis]. Eskişehir, Turkey: Anadolu University Graduate School of Educational Sciences. 
Ergünay, O., Adıgüzel, O.C. (2019a). The challenges of beginning teachers in their first year of teaching career and their sources. Egitimde Nitel Araştırmalar Dergisi-Journal of Qualitative Research in Education, 7(3), 1080-1099. https://doi.org/10.14689/issn.2148624.1.7c.3s.8m

Ergünay, O., Adıgüzel, O.C. (2019b). The first year in teaching: Changes in beginning teachers' visions and their challenges. Qualitative Research in Education, 8(3), 276. https://doi. org/10.17583/qre.2019.4016

Fairbanks, C.M., Duffy, G.G., Faircloth, B.S., He, Y., Levin, B., Rohr, J., Stein, C. (2010). Beyond knowledge: Exploring why some teachers are more thoughtfully adaptive than others. Journal of Teacher Education, 61(2), 161-171. https://doi.org/10.1177/0022487109347874

Hammerness, K. (2014). Visions of good teaching. In: S. Feiman-Nemser, E. Tamir, K. Hammerness (Eds.), Inspiring teaching: Preparing teachers to succeed in mission-driven schools (pp. 103-121). Cambridge: Harvard Education.

Hammerness, K. (2006). Seeing through teachers' eyes: Professional ideals and classroom practices. New York: Teachers College.

Kosnik, C., Beck, C. (2009). Priorities in teacher education. New York: Routledge.

Kennedy, M.M. (2006). Knowledge and vision in teaching. Journal of Teacher Education, 57(3), 205-211. https://doi.org/10.1177/0022487105285639

Mockler, N. (2005). Trans/forming teachers: New professional learning and transformative teacher professionalism. Journal of In-Service Education, 31(4), 733-746. https://doi.org/10 $.1080 / 13674580500200380$

MoNE. (2018). Turkey's education vision 2023. Retrieved from: https://planipolis.iiep.unesco. org/sites/planipolis/files/ressources/turkey_education_vision_2023.pdf

OECD. (2016). Supporting teacher professionalism: Insights from TALIS 2013, TALIS. Paris: OECD. https://doi.org/10.1787/97892642486o1-en

Parsons, S.A., Vaughn, M., Malloy, J.A., Pierczynski, M. (2017). The development of teachers' visions from preservice into their first years teaching: A longitudinal study. Teaching and Teacher Education, 64, 12-25. https://doi.org/10.1016/j.tate.2017.01.018

Ro, J. (2020). Curriculum, standards and professionalisation: The policy discourse on teacher professionalism in Singapore. Teaching and Teacher Education, 91, 103056. https://doi. org/10.1016/j.tate.2020.103056

Sachs, J. (2016). Teacher professionalism: Why are we still talking about it?. Teachers and Teaching: Theory and Practice, 22(4), 413-425. https://doi.org/10.1080/13540602.2015.1082732

Shulman, L. (2006). Foreword. In: K. Hammerness. Seeing through teachers' eyes: Professional ideals and classroom practices, (pp. vii-x). New York: Teachers College. 